\title{
Comparison of del Nido Cardioplegia with Blood Cardioplegia in Coronary Artery Bypass Grafting Combined with Mitral Valve Replacement
}

\author{
Ali Aycan Kavala', MD; Saygin Turkyilmaz', MD
}

DOI: $10.21470 / 1678-9741-2018-0152$

\begin{abstract}
Objective: To compare del Nido cardioplegia (DNC) with blood cardioplegia (BC) in coronary artery bypass grafting (CABG) combined with mitral valve replacement.

Methods: A 3-year single-center retrospective cohort study was carried out. Subjects who underwent CABG (up to triple bypass) combined with mitral valve replacement were divided into DNC and BC groups. Each group had thirty subjects.

Results: Both groups demonstrated similar baseline characteristics, including age, gender, cardiac/non-cardiac comorbidity, and preoperative echocardiographic parameters. Compared with the BC group, the DNC group demonstrated significantly lower cardioplegia volume $(B C=1130.00 \pm 194.1$ $\mathrm{mL}$, DNC $=884.33 \pm 156.8 \mathrm{~mL}, P=0.001)$, cardiopulmonary bypass time $(D N C=110.90 \pm 12.52 \mathrm{~min}, B C=121.70 \pm 13.57 \mathrm{~min}, P=0.002$ ), aortic clamp time $(\mathrm{DNC}=91.37 \pm 11.58 \mathrm{~min}, \mathrm{BC}=101.37 \pm 13.87$ $\min , P=0.004)$, and need for intraoperative defibrillation (DNC =
\end{abstract}

6 events, $B C=21$ events, $P=0.001)$. Postoperative creatine kinase$M B$ levels and troponin levels were significantly lower in the DNC group than in the BC group. Postoperative haemoglobin and haematocrit levels were significantly higher in the DNC group than in the BC group. The intubation period (hours) in intensive care unit (ICU) was significantly small in the BC group (DNC = 8.13 $\pm 12.21, B C=6.82 \pm 1.57, P=0.037$ ); however, ICU stay, total hospital stay, and postoperative complication rates were not significantly different between them. At pre-discharge echocardiography, the DNC group demonstrated significantly higher ejection fraction rates than the $B C$ group $(47.79 \pm 5.50$ and 45.72 \pm 5.86 , respectively, $P=0.005$ ).

Conclusion: DNC presented better intraoperative and postoperative parameters and it is an effective and safe alternative to BC for CABG combined with mitral valve replacement.

Keywords: Mitral Valve/Surgery. Coronary Artery Bypass. Heart Arrest, Induced. Cardioplegic Solutions. Treatment Outcome.

\begin{tabular}{llll}
\hline \multicolumn{2}{l}{ Abbreviations, acronyms \& symbols } & & \\
\hline BC & $=$ Blood cardioplegia & Htc & $=$ Haematocrit \\
CABG & $=$ Coronary artery bypass grafting & ICU & $=$ Intensive care unit \\
CK-MB & $=$ Creatine kinase-MB & NCSS & $=$ Number Cruncher Statistical System \\
CPB & $=$ Cardiopulmonary bypass & NYHA & $=$ New York Heart Association \\
DNC & $=$ Del Nido cardioplegia & RBCs & $=$ Red blood cells \\
EF & $=$ Ejection fraction & SD & $=$ Standard deviation \\
FFP & $=$ Fresh frozen plasma & TIA & $=$ Transient ischemic attack \\
Hgb & $=$ Haemoglobin & & \\
\hline
\end{tabular}

${ }^{1}$ Department of Cardiovascular Surgery, Bakirkoy Dr. Sadi Konuk Training and Research Hospital, Istanbul, Turkey.

This study was carried out at Department of Cardiovascular Surgery, Bakirkoy Dr. Sadi Konuk Training and Research Hospital, Istanbul, Turkey.
Correspondence Address:

Saygin Turkyilmaz

Department of Cardiovascular Surgery

Bakirkoy Dr Sadi Konuk Training and Research Hospital Dr. Tevfik Saglam Cad, no: 11, Bakirkoy, Istanbul, Turkey Zip code: 34147

E-mail:sygnty@hotmail.com 


\section{INTRODUCTION}

Open cardiac procedures mostly require cardiopulmonary bypass (CPB) to maintain the blood supply during surgery ${ }^{[1]}$. Cardioplegia is a state of cardiac arrest and cardiac protection induced by the infusion of cardioplegia solution into the myocardium and involves the cessation of myocardial contractions. During cardioplegia, ischaemia occurs in myocardial tissue ${ }^{[2]}$. After cross-clamp removal and reperfusion is initiated, a degree of ischaemia/reperfusion injury occurs, which is responsible for most of the complications of cardiac surgery ${ }^{[3]}$.

Several cardioplegia solutions exist with different compositions. However, there is no standard for the optimal composition and delivery technique ${ }^{[4]}$. Blood cardioplegia $(B C)$, which is the mixture of the subject's oxygenated blood (80\%) and a crystalloid solution (20\%), is the most widely used cardioplegia type ${ }^{[1]}$. The del Nido solution was formulated by researchers from the University of Pittsburgh (Pittsburgh, PA, USA) in the early $1990 \mathrm{~s}^{[5]}$. As a calcium-free, hyperkalemic, modified depolarizing solution, it was specifically formulated for paediatric cardiac surgery ${ }^{[6]}$. The del Nido solution contains a base solution of Plasma-Lyte and a crystalloid component. The use of solutions has started to increase in recent years for adults. A recent meta-analysis demonstrated significant advantages of the del Nido solution over BC in adults for several parameters ${ }^{[1]}$. However, the data regarding the use of del Nido solution in combined coronary artery bypass grafting (CABG) and mitral valve replacement are limited. The aim of the present study is to compare the del Nido cardioplegia (DNC) with BC in CABG combined with mitral valve replacement surgery.

\section{METHODS}

A 3-year retrospective cohort study was performed in a single tertiary academic center, Bakirkoy Dr. Sadi Konuk Education and Research Hospital, between December 2014 and December 2017. The study protocol was approved by the same hospital's ethics board.

Subjects in all age groups who underwent combined CABG (up to triple bypass) and mitral stenosis surgery were included in the study. Exclusion criteria were as follows:

- Previous cardiac surgery (open)

- Aortic insufficiency

- Concomitant procedures (e.g., aortic annulus enlargement, ascending aorta replacement, more than single-valve surgery)

- Tricuspid annuloplasty

- Subjects who underwent 4 or more bypass grafts performed during CABG surgery

The following demographic data and preoperative parameters were included: the subject's age, gender, New York Heart Association (NYHA) functional status, smoking and alcohol consumption status, body mass index, and comorbid diseases (hypertension, dyslipidaemia, diabetes mellitus, chronic obstructive pulmonary disease, and renal insufficiency). The preoperative previous stroke status, preoperative cardiac rhythm (atrial fibrillation, sinus rhythm, etc.), and preoperative echocardiogram parameters (ejection fraction [EF], valve area, valve gradient, presence/absence of atrial thrombus, and valve insufficiency) were also noted. For the study period, subjects who met the inclusion criteria for the DNC group were compared with the same number of subjects who had previously received $\mathrm{BC}$ by the same surgeon and met the inclusion criteria as well.

\section{Composition of del Nido and Blood Cardioplegia Solutions}

Del Nido solution is composed of mixed blood and PlasmaLyte A (1:4) (total volume: $1060 \mathrm{~mL}$ ). Mannitol (3.26 g), potassium chloride $(\mathrm{K}, 26 \mathrm{mEq})$, magnesium sulphate $(\mathrm{Mg}, 2 \mathrm{~g})$, lidocaine (130 mg), and sodium bicarbonate $(13 \mathrm{mEq})$ were added to the del Nido solution. BC solution consists of mixed blood and Ringer's lactate (1:4) (total volume: $550 \mathrm{~mL}$ ). Mannitol (10 g), potassium chloride $(\mathrm{K}, 46 \mathrm{mEq})$, magnesium sulphate $(2.5 \mathrm{~g})$, lidocaine (40 mg), and sodium bicarbonate $(1 \mathrm{mEq})$ were added to the $\mathrm{BC}$ solution.

\section{Surgical Procedure}

All subjects underwent a full sternotomy for surgical access under transoesophageal echocardiogram guidance. Cardioplegia solution was delivered by antegrade cardioplegia cannula. The velocity was $200 \mathrm{~mL} / \mathrm{min}$ and the solution's temperature was between 8-14 C degrees. The BC $(1000 \mathrm{~mL})$ solution was administered antegradely every 15 to 20 minutes. A single dose $(1000 \mathrm{~mL}$ ) of the del Nido solution was administered antegradely. After the surgeon completed the distal coronary anastomoses, a left atriotomy was performed to expose and excise the mitral valve. The annulus of the mitral valve was sized, and the prosthesis was sutured to the annulus with 25 coated, braided polyester stitches. The correct positioning was confirmed and the left atrium was closed in the standard fashion. The de novo mitral valve competency was assessed using transoesophageal echocardiography. Once the competency of the valve was confirmed, the cross-clamp was removed. A proximal coronary anastomosis was performed with a side clamp. After the surgery, the subjects were transferred to the intensive care unit and they were extubated 6-8 hours postoperatively. None of the subjects with preoperative atrial fibrillation underwent a maze procedure.

The intraoperative parameters were recorded, including aortic clamp time, CPB time, cardioplegia volume, bypass graft number, use of intraoperative defibrillation, and use of inotropic support (adrenalin/other).

Creatine kinase-MB (CK-MB) and troponin T, blood count (fresh frozen plasma [FFP], red blood cells [RBCS], and thrombocytes), and blood creatinine levels were assessed at 1, 6, 12, and 24 hours postoperatively. Haemoglobin ( $\mathrm{Hgb})$, haematocrit (Htc), glucose, and $\mathrm{K}$ levels were assessed at 6 and 12 hours postoperatively.

Complications such as myocardial infarction, acute renal insufficiency, atrial fibrillation, other arrhythmias, respiratory insufficiency, transient ischemic attack (TIA)/stroke, the need for a pacemaker, reoperation due to haemorrhage, infection, and death were noted.

The length of total intensive care and hospital stays was noted. All subjects underwent an echocardiographic assessment for $E F$ and valve function before discharge from the hospital. 


\section{Statistical Analysis}

The Number Cruncher Statistical System (NCSS) 2007 (Kaysville, Utah, USA) was used for statistical analysis. Descriptive statistical methods (mean, standard deviation [SD], median, frequency, ratio, minimum, and maximum) were used. Quantitative data with normal distribution were compared using Student's t-test, and the comparison of quantitative data without normal distribution was performed using Mann-Whitney $\mathrm{U}$ test. Comparisons in groups for data with normal distribution were performed using paired-samples t-test, and comparisons in groups for data without normal distribution were performed using Wilcoxon sign test. For qualitative data, Pearson's chisquare test, Fisher's exact test, and Fisher-Freeman-Halton test were used. A $P$-value less than 0.05 was considered significant.

\section{RESULTS}

For the study period, 30 subjects met the inclusion criteria for the DNC group (combined CABG [ $\leq 3$ bypass grafts] and mitral stenosis surgery). The data were compared with 30 subjects who had previously received $\mathrm{BC}$ by the same surgeon and met the inclusion criteria. Twenty-two subjects were excluded from the study.

The subjects' baseline characteristics are presented in Table 1. The mean age of DNC and BC groups was $69.53 \pm 6.73$ and $67.63 \pm 5.56$ years, respectively, $(P=0.272)$. The subjects did not differ in terms of sex distribution ( $P=0.432)$, NYHA functional status ( $P=1.000)$, or cardiac and non-cardiac comorbidities. The groups also did not differ in preoperative echocardiographic parameters. The preoperative EF (\%) of DNC and BC groups was $48.63 \pm 5.61$ and $47.20 \pm 7.36 \%$, respectively, $(P=0.400)$. The

Table 1. Subjects baseline characteristics according to cardioplegia type.

\begin{tabular}{|c|c|c|c|c|}
\hline & & \multicolumn{2}{|c|}{ Cardioplegia type } & \multirow{2}{*}{$P$} \\
\hline & & Del Nido $(n=30)$ & Blood $(n=30)$ & \\
\hline \multirow{2}{*}{ Age } & Min-max (median) & $54-81(70)$ & $54-80(67)$ & ${ }^{\mathrm{a}} 0.272$ \\
\hline & Mean \pm SD & $69.53 \pm 6.73$ & $67.63 \pm 5.56$ & \\
\hline \multirow{2}{*}{ Gender } & Female & $11(36.7)$ & $14(46.7)$ & ${ }^{b} 0.432$ \\
\hline & Male & $19(63.3)$ & $16(53.3)$ & \\
\hline \multirow{4}{*}{ NYHA functional status } & Class 1 & $2(6.7)$ & $2(6.7)$ & ${ }^{c} 1.000$ \\
\hline & Class 2 & $11(36.7)$ & $10(33.3)$ & \\
\hline & Class 3 & $15(50)$ & $15(50)$ & \\
\hline & Class 4 & $2(6.7)$ & $3(100)$ & \\
\hline \multicolumn{5}{|l|}{ Cardiac comorbidity } \\
\hline \multicolumn{2}{|l|}{ Hypertension } & $23(76.7)$ & $22(73.3)$ & ${ }^{b} 0.766$ \\
\hline \multicolumn{2}{|l|}{ Dyslipidemia } & $18(60)$ & $16(53.3)$ & ${ }^{b} 0.602$ \\
\hline \multicolumn{2}{|l|}{ Rhythm-atrial fibrillation } & $8(26.7)$ & $9(30)$ & ${ }^{b} 0.774$ \\
\hline \multicolumn{2}{|l|}{ Mitral valve insufficiency } & $5(16.7)$ & $4(13.3)$ & ${ }^{d} 1.000$ \\
\hline \multicolumn{5}{|l|}{ Non-cardiac comorbidity } \\
\hline \multicolumn{2}{|l|}{ Tobacco use } & $15(50)$ & $17(56.7)$ & ${ }^{\mathrm{b}} 0.605$ \\
\hline \multicolumn{2}{|l|}{ Alcohol consumption } & $4(13.3)$ & $3(10)$ & d1.000 \\
\hline \multicolumn{2}{|l|}{ Diabetes mellitus } & $16(53.3)$ & $12(40)$ & ${ }^{b} 0.301$ \\
\hline \multicolumn{2}{|c|}{ Chronic obstructive pulmonary disease } & $7(23.3)$ & $5(16.7)$ & ${ }^{b} 0.519$ \\
\hline \multicolumn{2}{|l|}{ Chronic renal insufficiency } & $3(10)$ & $2(6.7)$ & ${ }^{d} 1,000$ \\
\hline \multicolumn{2}{|l|}{ Preoperative TIA or stroke } & $2(6.7)$ & $3(10)$ & ${ }^{d} 1,000$ \\
\hline \multicolumn{5}{|c|}{ Preoperative echocardiographic parameters } \\
\hline \multirow{2}{*}{ Preoperative ejection fraction (\%) } & Min-max (median) & $35-60(49)$ & $30-55(49)$ & ${ }^{\mathrm{a}} 0.400$ \\
\hline & Mean \pm SD & $48.63 \pm 5.61$ & $47.20 \pm 7.36$ & \\
\hline \multirow{2}{*}{ Preoperative valvular area $\left(\mathrm{cm}^{2}\right)$} & Min-max (median) & $0,7-1,5(1,1)$ & $0.7-1.5(1.1)$ & ${ }^{\mathrm{a}} 0.376$ \\
\hline & Mean $\pm S D$ & $1.06 \pm 0.24$ & $1.11 \pm 0.23$ & \\
\hline \multirow{2}{*}{ Preoperative gradient (mm/HG) } & Min-max (median) & 7-12 (9) & $7-12(9)$ & ${ }^{\mathrm{a}} 0.249$ \\
\hline & Mean $\pm S D$ & $9.33 \pm 1.37$ & $8.93 \pm 1.29$ & \\
\hline
\end{tabular}

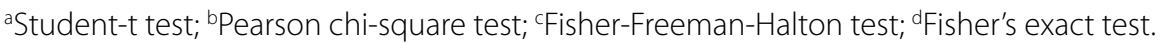

$\mathrm{NYHA}=$ New York Heart Association; $\mathrm{SD}=$ standard deviation; $\mathrm{TIA}=$ transient ischemic attack 
preoperative valvular area in DNC and BC groups was 1.06 \pm 0.24 and $1.11 \pm 0.23 \mathrm{~cm}^{2}$, respectively, $(P=0.376)$. And the preoperative gradient $(\mathrm{mmHg})$ for DNC and BC groups was $9.33 \pm 1.37$ and $8.93 \pm 1.29$, respectively, $(P=0.249)$.

The intraoperative data are presented in Table 2. The number of bypass grafts and mitral valve replacement types did not differ between the groups ( $P=0.927$ and $P=0.100$, respectively). Compared with the BC group, the DNC group demonstrated significantly lower cardioplegia volume $(B C=1130.00 \pm 194.1$ $\mathrm{mL}$ and $\mathrm{DNC}=884.33 \pm 156.8 \mathrm{~mL}, P=0.001), C P B$ time (DNC
$=110.90 \pm 12.52 \mathrm{~min}$ and $\mathrm{BC}=121.70 \pm 13.57 \mathrm{~min}, P=0.002)$ (Figure 1), aortic clamp time (DNC $=91.37 \pm 11.58 \mathrm{~min}$ and $B C=101.37 \pm 13.87 \mathrm{~min}, P=0.004$ ) (Figure 2), and number of intraoperative defibrillation procedures (DNC $=6$ cases and BC $=21$ cases, $P=0.001$ ).

After surgery, the subjects were transferred to the intensive care unit. Biochemical parameters for the first postoperative day are presented in Table 3. The CK-MB levels at 1 and 24 hours postoperatively were significantly lower in the DNC group (DNC $=5.82 \pm 4.72 \mathrm{ng} / \mathrm{mL}$ and $\mathrm{BC}=7.27 \pm 4.69 \mathrm{ng} / \mathrm{mL}, P=0.041$, and DNC

Table 2. Intraoperative data according to cardioplegia type.

\begin{tabular}{|c|c|c|c|c|}
\hline & & \multicolumn{2}{|c|}{ Cardioplegia type } & \multirow{2}{*}{$P$} \\
\hline & & Del Nido $(n=30)$ & Blood $(n=30)$ & \\
\hline \multirow{3}{*}{ No. bypass graft } & 1 & $3(10)$ & $3(10)$ & ${ }^{c} 0.927$ \\
\hline & 2 & $14(46.7)$ & $16(53.3)$ & \\
\hline & 3 & $13(43.3)$ & $11(36.7)$ & \\
\hline \multirow{2}{*}{ Cardioplegia volume (mL) } & Min-max (median) & 700-1350 (930) & $1000-1500(1000)$ & ${ }^{e} 0.001^{* *}$ \\
\hline & Mean \pm SD & $884.33 \pm 156.8$ & $1130.00 \pm 194.1$ & \\
\hline \multirow{2}{*}{ Cardiopulmonary bypass time (min) } & Min-max (median) & $85-132(112.5)$ & $95-150(120.5)$ & ${ }^{\mathrm{a}} 0.002^{* *}$ \\
\hline & Mean $\pm S D$ & $110.90 \pm 12.52$ & $121.70 \pm 13.57$ & \\
\hline \multirow{2}{*}{ Aortic clamp time (min) } & Min-max (median) & $68-110(90)$ & $75-128(105)$ & ${ }^{\mathrm{a}} 0.004^{* *}$ \\
\hline & Mean $\pm S D$ & $91.37 \pm 11.58$ & $101.37 \pm 13.87$ & \\
\hline \multicolumn{2}{|l|}{ Intraoperative defibrillation } & $6(20)$ & $21(70)$ & ${ }^{\mathrm{b}} 0.001^{* *}$ \\
\hline \multirow{2}{*}{ Mitral valve replacement type } & Mechanic valve & $7(23.3)$ & $13(43.3)$ & b0.100 \\
\hline & Bioprosthetic valve & $23(76.7$ & $17(56.7)$ & \\
\hline
\end{tabular}

aStudent-t test; ${ }^{\text {PPearson }}$ chi-square test; 'Fisher-Freeman-Halton test; ${ }^{~}$ Mann-Whitney $U$ test

${ }^{*} P<0.01 ; \mathrm{SD}=$ standard deviation

Cardiopulmonary bypass time ( $\mathrm{min})$

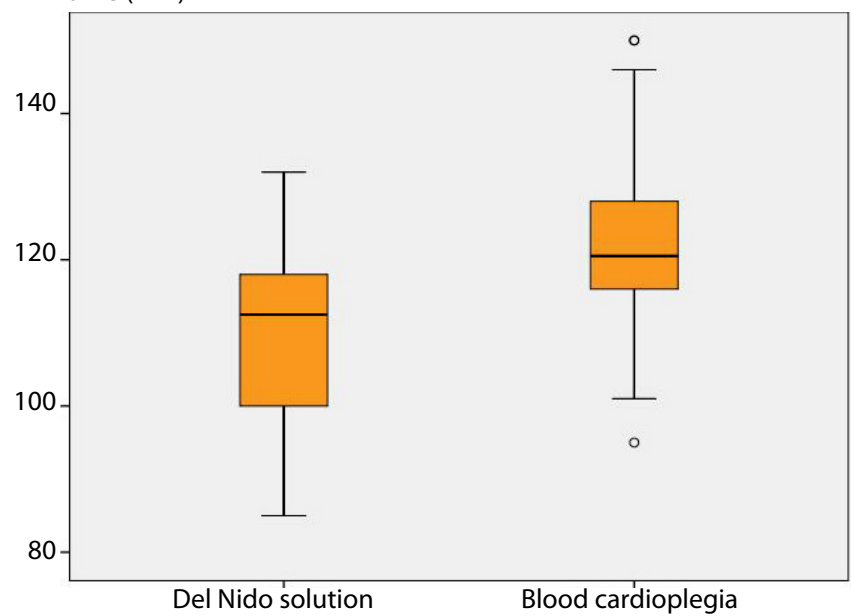

Fig. 1 - Comparison of cardiopulmonary bypass time (min) between del Nido cardioplegia and blood cardioplegia.

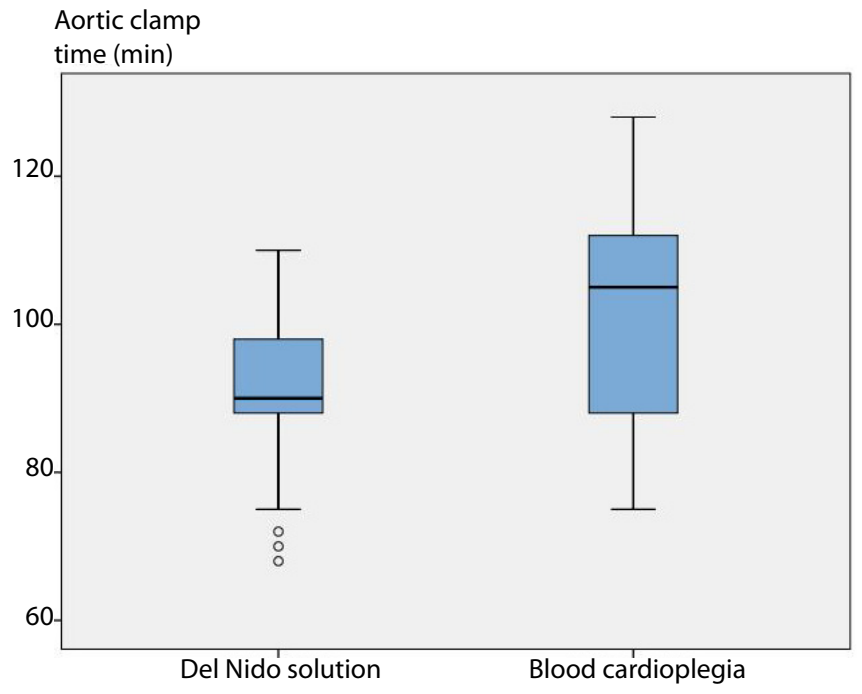

Fig. 2 - Comparison of aortic clamp time (min) between del Nido cardioplegia and blood cardioplegia. 
Table 3. Postoperative biochemical parameters according to cardioplegia type.

\begin{tabular}{|c|c|c|c|}
\hline & \multicolumn{2}{|c|}{ Cardioplegia type } & \multirow[b]{2}{*}{$P$} \\
\hline & Del Nido $(n=30)$ & Blood $(n=30)$ & \\
\hline \multirow{2}{*}{ Inotropic support in first 24 hours } & Norepinephrine $(\mathrm{n})$ & $3(10)$ & ${ }^{d} 1.000$ \\
\hline & Other inotropes (n) & $6(20)$ & b0.542 \\
\hline \multirow{2}{*}{ CK-MB (ng/mL), $1^{\text {st }}$ hour } & Min-max (median) & $2.4-25(5.8)$ & ${ }^{\mathrm{e}} 0.041^{*}$ \\
\hline & Mean \pm SD & $7.27 \pm 4.69$ & \\
\hline \multirow{4}{*}{ CK-MB (ng/mL), 24 hour } & Min-max (median) & $9.1-50(17.4)$ & ${ }^{e} 0.001^{* *}$ \\
\hline & Mean \pm SD & $17.53 \pm 7.26$ & \\
\hline & Difference & $10.27 \pm 5.14$ & ${ }^{\mathrm{e}} 0.004^{* *}$ \\
\hline & $P$ & ${ }^{f} 0.001^{* *}$ & \\
\hline \multirow{2}{*}{ Troponin $\mathrm{T}(\mathrm{ng} / \mathrm{mL}), 1^{\text {st }}$ hour } & Min-max (median) & $0.05-1.2(0.16)$ & e 0.099 \\
\hline & Mean \pm SD & $0.24 \pm 0.25$ & \\
\hline \multirow{4}{*}{ Troponin T (ng/mL), 24 ${ }^{\text {th }}$ hour } & Min-max (median) & $0.1-6(0.5)$ & ${ }^{e} 0.001^{* *}$ \\
\hline & Mean \pm SD & $0.67 \pm 1.03$ & \\
\hline & Difference & $0.44 \pm 0.87$ & ${ }^{\mathrm{e}} 0.001^{* *}$ \\
\hline & $P$ & f $0.001^{* *}$ & \\
\hline \multirow{2}{*}{ Haemoglobin $(\mathrm{g} / \mathrm{dL}), 6^{\text {th }}$ hour } & Min-max (median) & 7.9-12.1 (10) & ${ }^{\mathrm{a}} 0.005^{* *}$ \\
\hline & Mean \pm SD & $9.80 \pm 1.28$ & \\
\hline \multirow{4}{*}{ Haemoglobin ( $\mathrm{g} / \mathrm{dL}), 24^{\text {th }}$ hour } & Min-max (median) & 8.7-11.7 (9.9) & ${ }^{\mathrm{a}} 0.001^{* *}$ \\
\hline & Mean \pm SD & $9.94 \pm 0.79$ & \\
\hline & Difference & $0.13 \pm 1.22$ & e 0.387 \\
\hline & $P$ & ${ }^{9} 0.554$ & \\
\hline \multirow{2}{*}{ Haematocrit, $6^{\text {th }}$ hour } & Min-max (median) & $24-36(29)$ & ${ }^{\mathrm{a}} 0.005^{* *}$ \\
\hline & Mean \pm SD & $29.10 \pm 3.75$ & \\
\hline \multirow{4}{*}{ Haematocrit, $24^{\text {th }}$ hour } & Min-max (median) & $26-35(29)$ & ${ }^{\mathrm{a}} 0.001^{* *}$ \\
\hline & Mean \pm SD & $29.60 \pm 2.36$ & \\
\hline & Difference & $0.50 \pm 3.60$ & ${ }^{\mathrm{e}} 0.457$ \\
\hline & $P$ & ${ }^{9} 0.453$ & \\
\hline \multirow{2}{*}{ Postoperative $24^{\text {th }}$ hour creatinine $(\mathrm{mg} / \mathrm{dL})$} & Min-max (median) & $0.7-5.1(1.05)$ & ${ }^{\mathrm{e}} 0.847$ \\
\hline & Mean \pm SD & $1.44 \pm 1.15$ & \\
\hline \multirow{2}{*}{$\mathrm{K}^{+}(\mathrm{mM}), 1^{\text {st }}$ hour } & Min-max (median) & $3.5-6.3(4.1)$ & ${ }^{\mathrm{e}} 0.031^{*}$ \\
\hline & Mean \pm SD & $4.40 \pm 0.83$ & \\
\hline \multirow{4}{*}{$\mathrm{K}^{+}(\mathrm{mM}), 24^{\text {th }}$ hour } & Min-max (median) & $3.4-6.4(4.1)$ & ${ }^{\mathrm{e}} 0.223$ \\
\hline & Mean $\pm S D$ & $4.47 \pm 0.89$ & \\
\hline & Difference & $0.06 \pm 0.47$ & ${ }^{\mathrm{e}} 0.132$ \\
\hline & $P$ & f0.591 & \\
\hline \multirow{2}{*}{ Glucose $(\mathrm{mg} / \mathrm{dL}), 6^{\text {th }}$ hour } & Min-max (median) & $85-296(128)$ & ${ }^{\mathrm{e}} 0.564$ \\
\hline & Mean \pm SD & $164.00 \pm 70.23$ & \\
\hline \multirow{4}{*}{ Glucose (mg/dL), $24^{\text {th }}$ hour } & Min-max (median) & $89-350(125)$ & ${ }^{e} 0.604$ \\
\hline & Mean \pm SD & $176.60 \pm 81.23$ & \\
\hline & Difference & $12.60 \pm 33.65$ & ${ }^{\mathrm{e}} 0.876$ \\
\hline & $P$ & f0.115 & \\
\hline
\end{tabular}

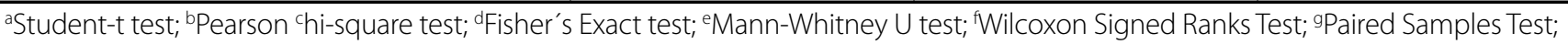

${ }^{*} P<0.05 ;{ }^{* *} P<0.01$.

$\mathrm{CK}-\mathrm{MB}=$ creatine kinase-MB; SD=standard deviation 
$=13.30 \pm 7.72 \mathrm{ng} / \mathrm{mL}$ and $\mathrm{BC}=17.53 \pm 7.26 \mathrm{ng} / \mathrm{mL}$, respectively, $P=0.001$ ). The troponin levels at 1 hour did not differ between the groups $(\mathrm{DNC}=0.13 \pm 0.05 \mathrm{ng} / \mathrm{mL}$ and $\mathrm{BC}=0.24 \pm 0.25 \mathrm{ng} / \mathrm{mL}$, $\left.P={ }^{e} 0.099\right)$. The troponin levels at 24 hours postoperatively were significantly lower in the DNC group (DNC $=0.28 \pm 0.41 \mathrm{ng} / \mathrm{mL}$ and $\mathrm{BC}=0.67 \pm 1.03 \mathrm{ng} / \mathrm{mL}, P=0.001$ ). The Hgb levels at 6 and 24 hours postoperatively were significantly higher in the DNC group than in the $B C$ group $(10.99 \pm 1.81 \mathrm{~g} / \mathrm{dL}$ vs. $9.80 \pm 1.28 \mathrm{~g} / \mathrm{dL}, P=0.005$, and $10.86 \pm 1.11 \mathrm{~g} / \mathrm{dL}$ vs. $9.94 \pm 0.79 \mathrm{~g} / \mathrm{dL}, P==^{\mathrm{a}} 0.001$, respectively). The postoperative Htc levels at 6 and 24 hours were significantly higher in the DNC group than in the BC group (32.43 \pm 4.94 vs $.29 .10 \pm 3.75, P=\mathrm{a} 0.005$, and $32.33 \pm 3.02$ vs. $29.60 \pm 2.36, P=0.001$, respectively). The postoperative $K$ levels were lower in the DNC group than in the $B C$ group at the first postoperative hour $(4.09 \pm 0.82 \mathrm{mM}$ vs. $4.40 \pm 0.83 \mathrm{mM}$, respectively, $P=0.031)$, whereas the K levels at 24 hours postoperatively did not differ between the groups ( $P=0.223$ ). There was no significant difference between the groups for inotropic support regardless of the inotropic agent used (e.g., epinephrine or other inotropic agent) $(P=1.000$ and $P=0.542$, respectively). The postoperative creatinine levels at 24 hours ( $\left.P={ }^{e} 0.847\right)$ and postoperative glucose levels at 6 and 24 hours ( $P=0.564$ and $P=0.604$, respectively) did not differ between the groups.

The intensive care unit intubation period (hours) was significantly lower in the $B C$ group $(D N C=8.13 \pm 12.21$ and $B C=$ $6.82 \pm 1.57, P=0.037$ ); however, the intensive care unit stay (days) was not different between the groups $(P=0.163)$ (Table 4).

The need for postoperative transfusion of RBCs or platelets did not differ between the groups $(P=0.754$ and $P=0.611$, respectively). The postoperative plasma transfusion rate was significantly higher in the DNC group than in the BC group $(P=0.001)$. Regarding complications, 17 events occurred in the DNC group and 25 events occurred in the BC group. All the comparisons for postoperative complications were not statistically significant.

At pre-discharge echocardiography, the DNC group demonstrated a significantly better EF percentage than the BC group (47.79 \pm 5.50 vs. $45.72 \pm 5.86$, respectively, $P=0.005$ ). The length of hospital stay was not different between the groups $(P=0.142)$.

\section{DISCUSSION}

During heart surgery, myocardial protection is an important consideration. Several cardioplegia solutions are available; however, there is no consensus concerning the optimal composition or technique ${ }^{[4]}$. The current study compared the safety and efficacy of DNC and BC in 30 matched subjects. Compared with the BC group, the DNC group demonstrated better intraoperative parameters, including lower cardioplegia volume, CPB time, aortic clamp time, and need for intraoperative defibrillation.

Common cardioplegia techniques include BC, histidinetryptophan-ketoglutarate solution, and $\mathrm{DNC}^{[1]}$. The del Nido solution contains Plasma-Lyte A and a crystalloid component. The base solution has the same electrolyte composition as extracellular fluid, and the crystalloid component contains mannitol, magnesium sulphate, sodium bicarbonate, potassium chloride, and lidocaine ${ }^{[5]}$. Lidocaine $\left(\mathrm{Na}^{+}\right.$channel blocker) and $\mathrm{Mg}^{2+}\left(\mathrm{Ca}^{2+}\right.$ competing agent/ $\mathrm{Ca}^{2+}$ channel blocker) decrease intracellular $\mathrm{Ca}^{2+}$ concentration, myocardial excitability, cellular metabolism, and energy consumption ${ }^{[7,8]}$. Although originally designed for a child's immature heart, the del Nido solution is offered as a new alternative to protect the ischaemic myocardium ${ }^{[6]}$.

Available literature did not demonstrate homogeneous data regarding DNC. However, initial experiences demonstrated its safety in CABG and isolated or combined valve surgery ${ }^{[1]}$. The use of DNC in CABG has been addressed in a few studies. Guajardo Salinas et al..$^{[9]}$ compared DNC $(n=134)$ with BC $(n=230)$. Except for the mean cardioplegia volume, mean number of cardioplegia doses, and defibrillation after cross-clamp removal, the groups demonstrated similar intraoperative and postoperative properties. The use of DNC resulted in a lower need for defibrillation in the subjects who underwent CABG. An equivalent efficiency of DNC was previously demonstrated by Timek et al..10], who reported the results for 100 propensityscore-matched subjects who underwent CABG. The use of DNC resulted in lower glucose levels than those for BC. In a previous report, Yerebakan et al..$^{[1]}$ demonstrated the safety of DNC in high-risk CABG surgery after acute myocardial infarction. Of 48 subjects who received DNC, the authors reported significantly shorter mean CPB and cross-clamp times; however, other intraoperative and postoperative data were similar between the groups.

Among the studies that addressed the use of DNC in mitral valve surgery, Yammine et al. ${ }^{[7]}$ compared modified DNC with whole BC in 79 matched subjects. The included subjects underwent valve procedures and/or CABG or mechanical valve implant. The postoperative 24-hour CK-MB levels were high in the DNC group. Except for the CK-MB levels, the operative parameters and postoperative comparisons were similar in both groups. Kim et al. ${ }^{[12]}$ compared the use of DNC with BC in 39 matched subjects. Although most of the subjects underwent isolated valvular surgery, other subjects who underwent aortic replacement surgery, CABG surgery, or had a congenital heart disease or tumour were also enrolled in the study. They've found no association between peak troponin I levels and left ventricular mass/aortic clamp time between the groups. Mick et al. ${ }^{[13]}$ compared the use of DNC with Buckberg cardioplegia in isolated aortic $(n=85)$ or mitral valve surgery $(n=110)$. The results demonstrated the safety of DNC in adult subjects who underwent isolated valve surgery. In aortic valve surgery, the use of DNC significantly reduced aortic clamp time, bypass time, and operating room time; however, in mitral valve surgery, the use of DNC was found to only be advantageous in case of postoperative insulin need. In both groups, the postoperative troponin levels as well as the left ventricular EF were similar.

Aortic valve procedures were also addressed in studies. Sorabella et al. ${ }^{[14]}$ compared the use of DNC $(n=52)$ with BC $(n=65)$ in isolated aortic valve procedures. Except for total cardioplegia volume, no significant difference was found between the groups. Of 54 matched subjects, Ota et al. ${ }^{[15]}$ reported shorter CPB and cross-clamp times when DNC was used. Postoperative 
Table 4. Postoperative data according to cardioplegia type.

\begin{tabular}{|c|c|c|c|}
\hline & \multicolumn{2}{|c|}{ Cardioplegia type } & \multirow[b]{2}{*}{$P$} \\
\hline & Del Nido $(n=30)$ & Blood $(n=30)$ & \\
\hline \multirow{4}{*}{$\begin{array}{l}\text { Postoperative red blood cell transfusion } \\
\text { (n) }\end{array}$} & None & $18(60)$ & ${ }^{\circ} 0.754$ \\
\hline & 1 unit & $7(23.3)$ & \\
\hline & 2 units & $2(6.7)$ & \\
\hline & 3 units & $3(10)$ & \\
\hline \multirow{4}{*}{ Postoperative plasma transfusion (n) } & None & $16(53.3)$ & ${ }^{\circ} 0.001^{* *}$ \\
\hline & 1 unit & $7(23.3)$ & \\
\hline & 2 units & $3(10)$ & \\
\hline & 3 units & $4(13.3)$ & \\
\hline \multirow{4}{*}{ Postoperative platelet transfusion (n) } & None & $27(90)$ & ${ }^{\circ} 0.611$ \\
\hline & 1 unit & $0(0.0)$ & \\
\hline & 2 units & $0(0.0)$ & \\
\hline & 3 units & $3(10)$ & \\
\hline \multirow{10}{*}{ Complications } & $\begin{array}{l}\text { Low cardiac output } \\
\text { syndrome }\end{array}$ & $3(10)$ & ${ }^{d} 1.000$ \\
\hline & Myocardial infarction & $1(3.3)$ & $\mathrm{d} 1.000$ \\
\hline & Acute renal insufficiency & $3(10)$ & d1.000 \\
\hline & Atrial fibrillation & $8(26.7)$ & b0.095 \\
\hline & Respiratory failure & $4(13.3)$ & ${ }^{\mathrm{d}} 0.671$ \\
\hline & Stroke/TIA & $1(3.3)$ & d 1.000 \\
\hline & Permanent pacemaker & $0(0.0)$ & - \\
\hline & Reoperation for bleeding & $3(10)$ & d1.000 \\
\hline & Infection & $1(3.3)$ & $\mathrm{d}_{1} .000$ \\
\hline & Hospital mortality & $1(3.3)$ & ${ }^{d} 1.000$ \\
\hline \multirow{2}{*}{$\begin{array}{l}\text { Intensive care unit intubation period } \\
\text { (hours) }\end{array}$} & Min-max (median) & $5-11(6.5)$ & ${ }^{e} 0.037^{*}$ \\
\hline & Mean $\pm S D$ & $6.82 \pm 1.57$ & \\
\hline \multirow{2}{*}{ Intensive care unit stay (days) } & Min-max (median) & $2-10(2)$ & ${ }^{e} 0.163$ \\
\hline & Mean $\pm S D$ & $2.53 \pm 1.57$ & \\
\hline \multirow{2}{*}{ Hospital stay (days) } & Min-max (median) & $5-10(6)$ & $\mathrm{e} 0.142$ \\
\hline & Mean $\pm S D$ & $6.30 \pm 1.58$ & \\
\hline \multirow{2}{*}{ Pre-discharge ejection fraction (\%) } & Min-max (median) & $30-55(45)$ & $e^{e} 0.005^{* *}$ \\
\hline & Mean $\pm S D$ & $45.72 \pm 5.86$ & \\
\hline
\end{tabular}

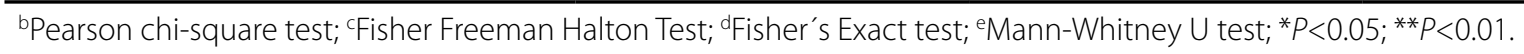

$\mathrm{SD}=$ standard deviation; $\mathrm{TIA}=$ transient ischemic attack

complications as well as length of intensive care and hospital stays did not differ between the groups. Vistarini et al. ${ }^{[16]}$ reported less atrial fibrillation, lower CK-MB levels, and lower insulin requirement associated with the use of DNC in minimally invasive aortic valve surgery. Hamad et al. ${ }^{[2]}$ evaluated the effect of DNC in CABG combined with aortic valve surgery in 25 subjects. CPB time, cross-clamp time, and postoperative CK-MB and troponin levels were lower in the surgeries with use of DNC.

The basic advantages of DNC are single-dose application and glucose-free ingredients ${ }^{[6]}$. DNC was administered as a single dose for subjects who underwent procedures of less than 90 minutes duration. The single-dose application decreased CPB 
and cross-clamp times. A recent meta-analysis involving 9 studies reported the effect of DNC in 1501 subjects (4 studies involved isolated valve procedures, 3 studies involved CABG procedures, and 2 studies reported valve procedures or $(A B G)$. The results of the meta-analysis reported shorter CPB and cross-clamp times when DNC was used ${ }^{[1]}$. Cardioplegia volume, blood glucose levels, ventilation time, and length of intensive care stay were also decreased for DNC when compared with those for BC. BC requires multiple interruptions, which is an additional factor for ischaemic damage. The single-dose application was associated with a lower cardioplegia volume and less haemodilution, which decreases the transfusion requirement according to literature ${ }^{[1,2]}$. In the present study, the need for RBCs and platelet transfusion rates were similar in DNC and BC groups. Although the postoperative plasma transfusion need was lower in the BC group, the importance of this finding could not be clearly described. Having glucose-free ingredients in the solution is important for subjects who have diabetes mellitus. However, no significant difference was observed between the groups in the present study.

The use of DNC demonstrated lower CK-MB and troponin levels, which are sensitive biomarkers for cardiac injury. The lower levels in our study were a sign of better myocardial protection. The DNC group also demonstrated higher Hgb and Htc levels; however, RBC transfusion rates were similar for both groups. In the present study, the use of DNC demonstrated similar postoperative complication rates and intensive care and hospital stay rates. Although the $\mathrm{BC}$ group demonstrated significantly shorter intensive care unit intubation period than the DNC group, this difference was not regarded as clinically significant. Before discharge, the subjects underwent an echocardiographic assessment. A higher EF rate in the DNC group was also a sign of better myocardial protection.

This study presents a single-center, single-surgeon experience in a retrospective design, and there are limitations related to such design. Long-term follow-up was not conducted, which made it difficult to interpret some findings such as lower cardiac marker levels and better postoperative EF rates. As an initial experience, our data added observational value, but there is a need for randomised, multicenter trials comparing different solutions in different cardiac procedures.

\section{CONCLUSION}

The current study results showed better intraoperative and postoperative chemical parameters when DNC was used. The need for a lower cardioplegia volume and an uninterrupted procedure are the main advantages of DNC. DNC is at least equivalent to $B C$ and it is a safe alternative to $B C$ in $C A B G$ combined with mitral valve surgery in adults.

\section{ACKNOWLEDGEMENTS}

We would like to thank Emire Bor (Empiar Statistics) for performing the statistical analysis of the study.

\section{Authors' roles $\&$ responsibilities}

AAK

Substantial contributions to the conception or design of the work; or the acquisition, analysis, or interpretation of data for the work; drafting the work or revising it critically for important intellectual content; final approval of the version to be published

ST

\begin{abstract}
Substantial contributions to the conception or design of the work; or the acquisition, analysis, or interpretation of data for the work; drafting the work or revising it critically for important intellectual content; final approval of the version to be published; agreement to be accountable for all aspects of the work in ensuring that questions related to the accuracy or integrity of any part of the work are appropriately investigated and resolved
\end{abstract}

\section{REFERENCES}

1. Li Y, Lin H, Zhao Y, Li Z, Liu D, Wu X, et al. Del Nido cardioplegia for myocardial protection in adult cardiac surgery: a systematic review and meta-analysis. ASAIO J. 2018;64(3):360-7.

2. Hamad R, Nguyen A, Laliberté É, Bouchard D, Lamarche Y, El-Hamamsy I, et al. Comparison of del Nido cardioplegia with blood cardioplegia in adult combined surgery. Innovations (Phila). 2017;12(5):356-62.

3. Gorjipour F, Dehaki MG, Totonchi Z, Hajimiresmaiel SJ, Azarfarin R, Pazoki-Toroudi $\mathrm{H}$, et al. Inflammatory cytokine response and cardiac troponin I changes in cardiopulmonary bypass using two cardioplegia solutions; del Nido and modified St. Thomas': a randomized controlled trial. Perfusion. 2017;32(5):394-402.

4. Ad N. Del Nido cardioplegia: ready for prime time in adult cardiac surgery? J Thorac Cardiovasc Surg. 2015;149(2):637-8.

5. Matte GS, del Nido PJ. History and use of del Nido cardioplegia solution at Boston Children's Hospital. J Extra Corpor Technol. 2012;44(3):98-103.

6. Kim K, Ball C, Grady P, Mick S. Use of del Nido cardioplegia for adult cardiac surgery at the Cleveland Clinic: perfusion implications. J Extra Corpor Technol. 2014;46(4):317-23.

7. Yammine M, Neely RC, Loberman D, Rajab TK, Grewal A, McGurk S, et al. The use of lidocaine containing cardioplegia in surgery for adult acquired heart disease. J Card Surg. 2015;30(9):677-84.

8. Pourmoghadam KK, Ruzmetov M, O'Brien MC, Piggott KD, Plancher G, Narasimhulu SS, et al. Comparing del Nido and conventional cardioplegia in infants and neonates in congenital heart surgery. Ann Thorac Surg. 2017;103(5):1550-6.

9. Guajardo Salinas GE, Nutt R, Rodriguez-Araujo G. Del Nido cardioplegia in low risk adults undergoing first time coronary artery bypass surgery. Perfusion. 2017;32(1):68-73.

10. TimekT, Willekes C, Hulme O, Himelhoch B, Nadeau D, Borgman A, et al. Propensity matched analysis of del Nido cardioplegia in adult coronary artery bypass grafting: initial experience with 100 consecutive patients. Ann Thorac Surg. 2016;101(6):2237-41.

11. Yerebakan H, Sorabella RA, Najjar M, Castillero E, Mongero L, Beck J, et al. Del Nido cardioplegia can be safely administered in high-risk coronary artery bypass grafting surgery after acute myocardial infarction: a propensity matched comparison. J Cardiothorac Surg. 2014;9:141.

12. Kim JS, Jeong JH, Moon SJ, Ahn H, Hwang HY. Sufficient myocardial protection of del Nido cardioplegia regardless of ventricular mass and 
myocardial ischemic time in adult cardiac surgical patients. J Thorac Dis. 2016;8(8):2004-10

13. Mick SL, Robich MP, Houghtaling PL, Gillinov AM, Soltesz EG, Johnston DR, et al. del Nido versus Buckberg cardioplegia in adult isolated valve surgery. J Thorac Cardiovasc Surg. 2015;149(2):626-34.

14. Sorabella RA, Akashi H, Yerebakan H, Najjar M, Mannan A, Williams MR, et al. Myocardial protection using del Nido cardioplegia solution in adult reoperative aortic valve surgery. J Card Surg. 2014;29(4):445-9.

15. Ota T, Yerebakan H, Neely RC, Mongero L, George I, Takayama H, et al. Short-term outcomes in adult cardiac surgery in the use of del Nido cardioplegia solution. Perfusion. 2016;31(1):27-33.

16. Vistarini N, Laliberté E, Beauchamp P, Bouhout I, Lamarche Y, Cartier R, et al. Del Nido cardioplegia in the setting of minimally invasive aortic valve surgery. Perfusion. 2017;32(2):112-7. 